\title{
Theoretical study of thermoelectric cooling system performance
}

\author{
A.E. Kabeel \\ Dep. of Mechanical Engineering, Tanta University \\ Tanta, Egypt \\ Kabeel6@hotmail.com \\ M. G. Mousa \\ Dep. of Mechanical Engineering, Mansoura University \\ Mansoura, Egypt \\ mgmousa@gmail.com \\ Moataz M.A. Elsayed \\ Higher Institute of Engineering \& Technology, New Damietta \\ Damietta, Egypt \\ eng.moataz86@yahoo.com
}

\begin{abstract}
This work provides a theoretical investigation to study the effect of different operational parameters on the performance of TE cooling system including the system COP and the rate of heat transfer. The parameters investigated are, the applied input power, inlet working fluid velocity, the arrangement of utilized TECs modules and fluid type. The geometry is created with ANSYS multi-physics software as a two-dimensional base case, it is consisted from two attached horizontal ducts of length $(520 \mathrm{~mm})$ and $(560 \mathrm{~mm})$, the interface surface between the two ducts contains three thermoelectric modules ( $4 \mathrm{~mm}$ height by $40 \mathrm{~mm}$ wide and $40 \mathrm{~mm}$ length). The distance between two consecutive thermoelectric modules $(150 \mathrm{~mm})$, the inlet and outlet duct diameter $(15 \mathrm{~mm})$ and the height of each duct $(10 \mathrm{~cm})$, the inlet voltage to thermoelectric modules ranges from $8.0 \mathrm{~V}$ to $12 \mathrm{~V}$ and the water inlet velocity to the two ducts from 0.001 to $0.01 \mathrm{~m} / \mathrm{s}$. Theoretical results showed that the overall COP of TE cooling system is increased with the applied input power up to $8.0 \mathrm{~W}$ then it decreases with input power up to $18 \mathrm{~W}$ after that it takes nearly a constant value, a noticeable enhancement in the COP is found when the three TECs are in use (Case 10) and the COP of TE cooling system using pure water and nanofluid with $0.05 \%$ of nanoparticles as coolants takes the maximum value.
\end{abstract}

Keywords: Thermoelectric cooler, COP, cooling system, input power, TECs arrangement, flow velocity.

\begin{tabular}{|c|l|c|l|}
\hline \multicolumn{2}{|l|}{ Nomenclature } \\
\hline $\mathrm{C}_{\mathrm{p}}$ & Specific heat, $\mathrm{J} / \mathrm{kg} \cdot{ }^{\circ} \mathrm{C}$ & \multicolumn{3}{|l|}{ Greek symbols } \\
\hline $\mathrm{COP}$ & Coefficient of performance & $\Phi$ & Particle volume fraction, $\%$ \\
\hline $\mathrm{I}$ & Electric current, $A$ & \multicolumn{2}{|c|}{ Subscripts } \\
\hline$\dot{\mathrm{m}}$ & Mass flow rate, $\mathrm{kg} / \mathrm{s}$ & $\mathrm{C}$ & Cooling \\
\hline $\mathrm{N}$ & Number of thermocouples in each stage & $\mathrm{C}$ & Cold-side \\
\hline $\mathrm{Q}$ & Rate of heat, $W$ & $\mathrm{E}$ & Electric \\
\hline $\mathrm{T}$ & Temperature,${ }^{\circ} \mathrm{C}$ & $\mathrm{H}$ & Heating \\
\hline $\mathrm{TE}$ & Thermoelectric & $\mathrm{H}$ & Hot-side \\
\hline $\mathrm{TEC}$ & Thermoelectric cooler & $\mathrm{J}$ & Junction \\
\hline $\mathrm{t}$ & Transient time, $s$ & $\mathrm{M}$ & Module \\
\hline $\mathrm{V}$ & Voltage, $V$ & $\mathrm{~N}$ & N-type semiconductor \\
\hline$\dot{V}$ & Volume flow rate, $\mathrm{m}^{3} / \mathrm{s}$ & $\mathrm{P}$ & P-type semiconductor \\
\hline$\dot{W}$ & Power, $W$ & & \\
\hline
\end{tabular}




\section{Introduction}

A thermoelectric cooler (TEC) is a solid condition heat pump based on Peltier effect [1] that refers to the generation of electrical current due to the difference in temperature between two junctions of dissimilar materials as shown in Fig. 1. A TEC consists of two legs, the first is ' $n$-form' that involves negative chargeable portable carriers in the shape of electrons, whereas the second is ' $p$-form' that involves positive charged portable carriers denominated holes. These pair legs are joined in series electrically, while thermally in parallel as viewed in Fig. 2.

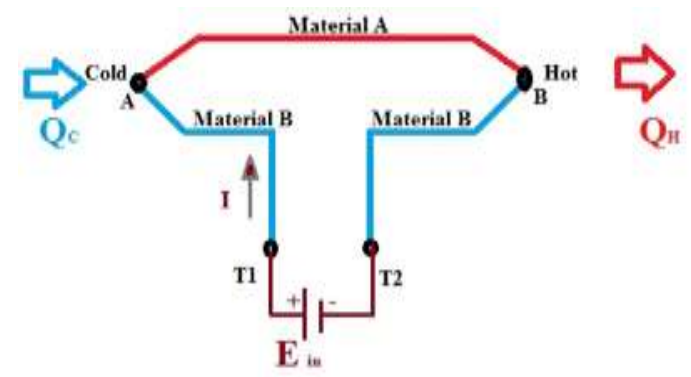

Fig. 1. Peltier Effect.

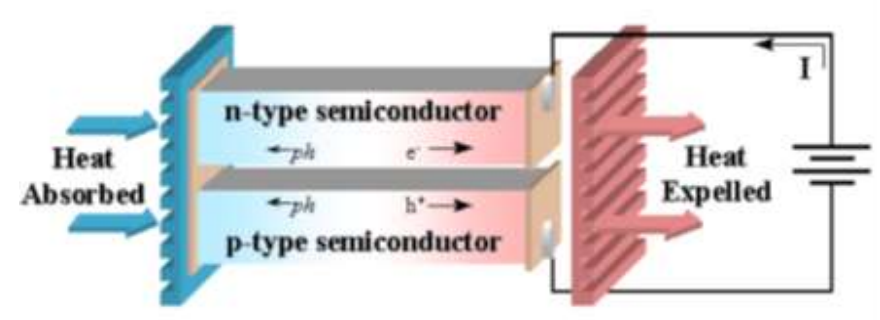

Fig. 2. Typical single stage cooler.

Thermoelectric coolers have many advantages including compactness, no moving parts, the dependence of COP on capacity, easy controllable cooling rate, vibration-free operation, precise temperature control and the possibility of reversible heating and cooling operations. The characteristics parameters of thermoelectric coolers are the power supply (voltage and current), the temperature difference between the hot and cold side and fluid flow rates over the sides and COP. The biggest obstacle for TECs is its low COP, but advanced materials with a higher quality of thermoelectric properties could subsequently make them better than traditional cooling systems.

There are many theoretical studies conducted to evaluate the performance and to investigate various applications of the TEC system. In this context, Clifton [2] used Thermoelectric Cooler Design which was a Microsoft Windows program in thermoelectric cooler devices design. This program was installed to be used as a fast model and for comparing different designs. Optimal coefficient of performance and maximal heat pumping can be obtained quickly. There were additional characteristics of this program as the facility to adapt material properties and dimensions of couples, analyzing arranged couples, and graphing performance variables. Wang et al. [3] derived a silicon microcooler model analytically in which Peltier cooling was coupled with heat conduction and heat generation in the silicon substrate. The effect of cooling potential of thermoelectric devices on the microcooler surface was obtained, delineated by maximum cooling heat flux.

Non-dominated Sorting Genetic Algorithm-II (NSGA-II) was used by Nain et al. [4] to obtain Pareto-optimal solutions in different three cases for ambient conditions. Mathematical model and the influence of ambient states on optimum performance were studied. The optimization results were confirmed by theoretical equations for ThermoElectric Coolers (TEC). It was terminated the possibility of performance optimization of a single stage TEC, applicable and had a great potential for practical TEC use. Virjoghe et al. [5] studied numerical simulation for several thermoelectric materials by using a finite element package ANSYS. It was shown that decreasing thermal conductivity would decrease the heat transfer between the two ends, Joule heating was reduced due to decreasing electrical resistivity. Moreover a larger Seebeck coefficient would enhance the heat removal. The boundary conditions for the Peltier effect in semiconductors were studied by Lashkevych and Gurevich [6] using potential barriers ( $\mathrm{p}-\mathrm{n}$ junction). The surface merge of charge carriers was analyzed for the electric current and the heat generation. Redmond [7] utilized computational method to explore the use of thermoelectric and/or microfluid for cooling hotspots or removing high heat fluxes in stacked. A thermal model of a 3-D full-bosomed chip with top and bottom dies and embedded ultrathin thermoelectric coolers were prepared. This analysis recommended that TECs can be applied for the cooling of hotspots in 3-D full-bosomed chip design. There was a cooling to $9{ }^{\circ} \mathrm{C}$ on the bottom chip of the hot spot without an applied current. An extra temperature reduction to $5.6{ }^{\circ} \mathrm{C}$ was occurred due to steady state active cooling with the current applied in the TEC, giving up a total of $14.6{ }^{\circ} \mathrm{C}$ steady state cooling. It was also determined that base TECs can heat the topmost hotspots in both steady state and cause a poor transient performance. Lam et al. [8] studied the analytic solutions of transient temperature allocations through semiconductor elements taking Thomson effect into consideration. By using the superposition technique and a certain transformation function the temperature distributions was obtained. This solution technique could be effective in obtaining temperature profile for a sample of TEC semiconductor material. Lamba et al. [9] derived an analytical model for cooling capacity, energy and exergy efficiencies, figure of merit and irreversibility considering Thomson effect. The temperature ratio effects and shape parameter on the 
performance variables was studied and it was compared with the energy efficiency using the genetic algorithm (GA).

Richard [10] improved a theoretical model that could determine the optimal performance of the discrete thermocouples in a simple linear arrange for a non-uniform heat distribution condition. This model was scaled and could be used to inspect growing complicated outlines to find feasibleness of the technique. With the aid of an allocated control ruling to the TEC, it had been displayed that the optimal performance could be closely estimated. This procedure accepted the appreciated local temperature values and determined the current loads to separate thermocouples to estimate maximal performance. The outcomes showed advanced performance all through the operating rule by $80 \%$ over a common TEC serial type. In many regimes, this enhancement was twice the conventional values. This enhancement could, at least, decrease the space between computed technology and cooling capacity. The results indicated a performance increase from this novel advance. Moreover, to obtain a control rule, the influences in effective thermal resistances changes were studied. The benefits potentiality of distributed control increased as lateral conduction was decreased. The transient time $\tau$ of a cascade thermoelectric cooler was computed by Ravich and Gordienko [11]. This applied procedure did not contain the heat equations solutions for semiconductor components. Using an analytical solution of the quadratic equation hold the transient time $\tau$ of a two-stage thermopile, the equation coefficients affected by semiconductor thermoelectric parameters as the specific heat of the thermopile materials and different parts sizes of the cooler. For any number of thermopile stages, the calculations were limited to the main problem of finding the eigen-values of two symmetrical matrices with order $\mathrm{N}$. The calculated transient time was matched with the experimental values for two-stage thermopiles. A finite element formulation of Joule heating, including Seebeck, Peltier and Thomson effects was analyzed with Antonova and Looman [12]. A multistage thermoelectric cooler analysis was executed to show the potential of ANSYS parametric analysis. A theoretical investigation of a two-stage semiconductor (TEM) was studied by Olivares-Robles et al. [13], which contains different numbers of thermocouples per each stage (pyramid -Styled TEM). Numbers of thermocouples for the two stages $\left(\mathrm{n}_{1}, \mathrm{n}_{2}\right)$, the electric currents flowing throughout each stage, the employed temperatures and the thermoelectric properties of the semiconductor materials were analyzed on the exergetic efficiency. The results showed a difference in the electric currents moving through each stage must with a ratio approximately 4.3 for the maximum thermal. The ratio between $n_{1} / n_{2}$ should be within eight.

A trapezoidal two-stage Peltier couples (TTPC) was presented by Lin and Jianlin [14] for two-stage thermoelectric cooling applications. For providing higher performance, TTPC based thermoelectric module reduced the inter-stage thermal resistance. The optimal design analyses were carried out by using an advanced mathematical model. The results indicated that the highest cooling capacity and coefficient of performance (COP) of TTPC Peltier were affected by couple leg length distribution proportion between the cold stage and hot stage in addition to the shape ratio of trapezoidal Peltier couple leg at hot stage. Furthermore, there was an optimal design of the TTPC to attain the optimized cooling capability and COP at a certain geometrical factors and working conditions. Wang et al. [15] studied the effects of geometrical structure and applied currents on a two-stage TEC performance, an optimization was developed to attain the maximum cooling capacity of the two-stage TEC. Nemati et al. [16] performed an exergetic analysis for an electrically separated two-stage thermoelectric cooler (STTEC). The effects of applied currents and geometric characteristics on the STTEC exergy and economic performance were studied. Moreover, a minimum cooling cost analyze was obtained.

Al-Kaby [17] studied theoretically the product of changing TE material limitations like thermal conductivity, resistivity and Seebeck coefficient on the COP of thermoelectric cooling system. The differential equations were resolved by the method of finite difference and by using a Quick Basic computer program the temperature distribution was calculated. The results showed that small increment of the input power $(\dot{W})$ would increase $\mathrm{Q}_{\mathrm{c}}$ dramatically and increase $\mathrm{Q}_{\mathrm{h}}$ gradually, as a result the optimal COP occurred at small values of $\dot{W}$. For commuter demand about minimizing system mass, volume, and cost to promote their marketing possibilities, Hendricks and Karri [18] determined the optimal design procedures for these systems. The relationships between COP, cooling capacity, and cooling heat flux requirements, upper boundaries, and critical differences in different p-type and n-type TE systems were investigated. Finally, the critical precept that micro-technologies and nano-technologies could play in enabling small scales of TE cooling systems in progressive vehicle and residential applications was analyzed. Thin-film thermoelectric cooling is a hopeful technology for justifying heat deposition in high performance chips. Long and Memik [19] presented a developed structure for an array of thinfilm thermoelectric coolers. It was found that the hot spot reduction in temperature was $10.6{ }^{\circ} \mathrm{C}$, as compared to traditional cooling techniques. The average temperature decreased by $8.6{ }^{\circ} \mathrm{C}$ when four customized pins were used on the package.

The performance of a TEM was presented into a larger model to design cooling systems for machine tool components by Gallo et al. [20] using a numerical modeling. The obtained results showed the validity of the numerical model for the considered TEM for different operating conditions and it was proven numerically the necessity of heat sinks in TEM systems, also heat sink performance for different fan conditions and TEM currents was numerically simulated in addition to the different cooling systems were utilized to cool the machine tool component. Francis et al. [21] made a thermoelectric refrigerator model maintained at $4^{\circ} \mathrm{C}$. The refrigerator 
performance was simulated using Matlab under different working conditions. Results showed that COP is a function of the temperature between the source and sink. For achieving high performance the temperature difference should be kept to the minimum. Liquid cooling garments (LCGs) showed several advantages over other types of personal cooling garments. Liquid-filled tubes extract excessive heat from the body. Water is cooled by passing through a block which is on contact with cold side of a thermoelectric. Azimi et al. [22] analyzed parametrically the thermal performance of a water block in the cooling system. The conjugated heat transfer had been numerically studied. Results showed that temperature difference versus number of fins and the block dimensions had increasing behavior. With inlet velocity magnitude, heat transfer performance decreased. Thermal conductivity of the block did not have considerable effect on the cooling system performance.

A qualified pulse operation of TEC for building space cooling applications was presented by Manikandan et al. [23]. A numerical model for TEC system was established for one-dimension unsteady state heat transfer. An average cooling power of $600 \mathrm{~W}$ was achieved when the COP was about 1.01 , which were $23.3 \%$ and $2.12 \%$ greater than the usual mode without current pulse of operation, respectively. One attempts for improving the TEC cooling performance was a gravity-assisted heat pipe (GAHP) that was attached on the hot side of TEC. Sun et al. [24] developed a mathematical model to study the impact of refrigerant filling ratio, TEC hot side temperature and air flow rate. It was showed that the optimum refrigerant filling ratio for maximum heat transfer was $134 \%$ and the cooling capacity was improved by increasing air flow rate. Cai et al. [25] studied a theoretical analysis for TE heat recovery unit, the cost performance model was evaluated. Overall thermal conductivity was determined analytically from steady-state modeling, where the optimum working parameters: quantity, filling factor, length of P-N legs and couple numbers of TEC were recognized. A mathematical analysis of an absorption cycle was investigated by Boukhanouf and Supasuteekul [26] using rejected heat from TEM to operate the cycle. The absorption cycle used $\mathrm{LiBr} / \mathrm{H}_{2} \mathrm{O}$ solution as the working couple with TEMs sandwiched between the generator and absorber. It was showed that thermoelectric modules would have the ability to supply the required heat for driving the absorption cycle and COP of the whole system could be larger than unity.

\section{Aim of the present work}

From the previous work, the optimum performance of TECs needs more study. There are many points can be used to maximize the performance such as using TE new materials, increasing heat removal from hot side. Moreover, the applications for TECs require more investigations and work. This work study theoretically the effect of operating parameters such as, input power, fluid flow rate, fluid type and the number and arrangements of working TE modules in TEC system on the performance of TEC system.

\section{Theoretical model}

Mastery of Computational Fluid Dynamics, CFD in handling complex flow and heat industrial problems is becoming ever more important. Competency in such a skill certainly brings about a steep learning curve for practicing engineers, who constantly face extreme challenges to come up with solutions to fluid flow and heat transfer problems without priority knowledge of the basic concepts and fundamental understanding of fluid mechanics and heat transfer.

Fig. 3 illustrates a schematic of the physical domain, with two attached horizontal ducts of length L1 and L2, the interface surface between the two ducts contains three thermoelectric modules. The distance between two consecutive thermoelectric modules $b$, the inlet and outlet duct diameter $d$ and the height of each duct $h$. The considered dimensions for the thermoelectric module are $4 \mathrm{~mm}$ height by $40 \mathrm{~mm}$ wide and $40 \mathrm{~mm}$ length.

Simulations are performed for the thermoelectric cooling system with two attached horizontal ducts of length L1 and L2 are 520 and $560 \mathrm{~mm}$, respectively, The distance between two consecutive thermoelectric modules b is $150 \mathrm{~mm}$, inlet and outlet duct diameter, $\mathrm{d}$ is $15 \mathrm{~mm}$, the inlet voltage to thermoelectric modules $\mathrm{V}(8 \mathrm{~V}$ to $12 \mathrm{~V})$ and the water inlet velocity to the two ducts $(0.001$ to $0.01 \mathrm{~m} / \mathrm{s})$. A mathematical model of heat transfer in the thermoelectric cooling system is shown in Fig. 4; has been adopted.

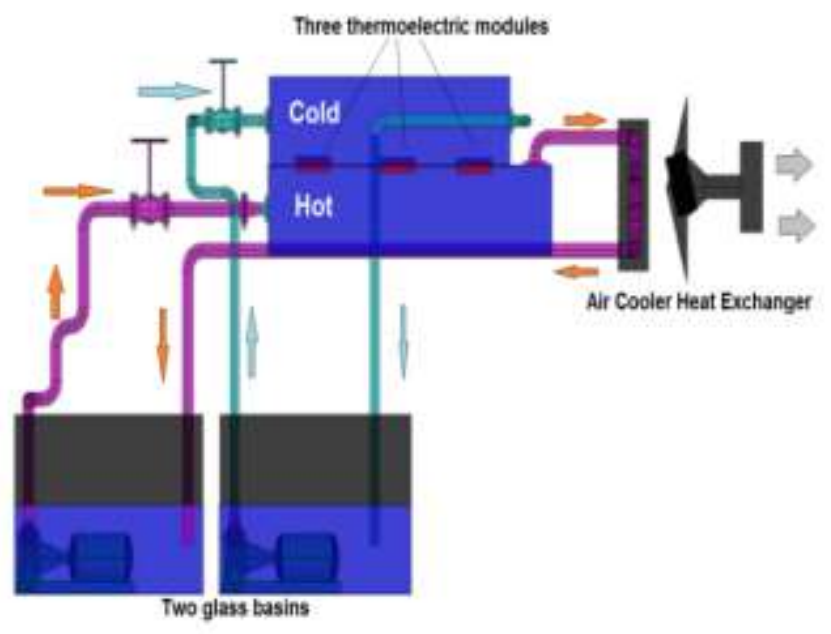

Fig. 3. Schematic diagram of thermoelectric cooling system. 


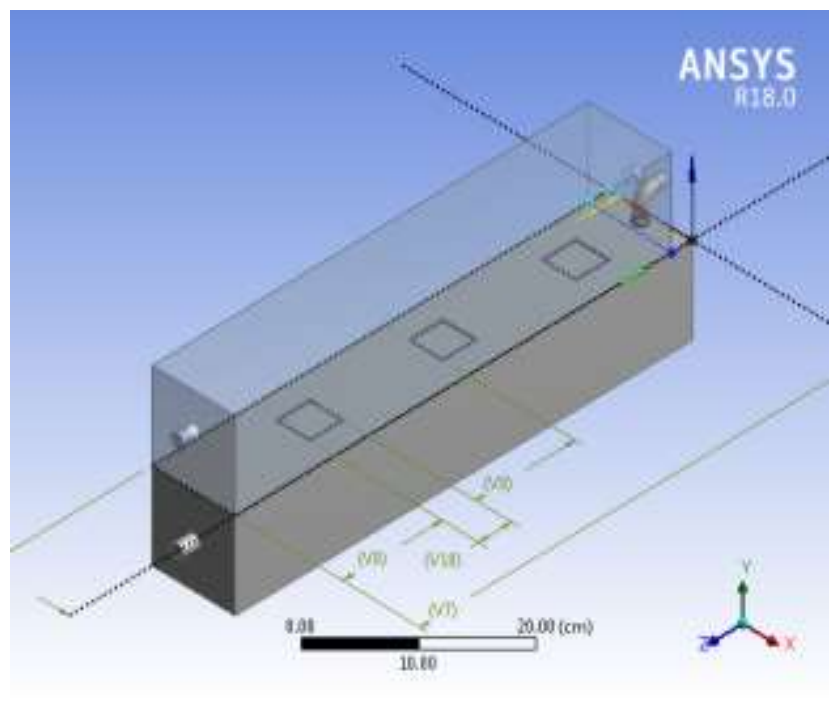

Fig. 4. Computational domain from ANSYS-Fluent 18.

\subsection{Mathematical modeling}

The following assumptions have been used to simplify the governing equations:

- Steady state 2-D fluid flow in the duct,

- Conduction heat transfer through interface walls is neglected,

- Negligible radiation effects, fluid.

- Constant thermo-physical properties of the working

\subsection{Governing equations}

Based on the foregoing assumptions, the governing equations in the Cartesian coordinates:

The continuity equation:

$$
\frac{\partial}{\partial x}(\rho u)+\frac{\partial}{\partial y}(\rho v)=0
$$

The Navier-Stokes equations in Cartesian coordinates are: $\mathrm{X}$-direction momentum equation:

$$
\frac{\partial}{\partial x}(\rho u u)+\frac{\partial}{\partial y}(\rho v u)=\frac{\partial p}{\partial x}+\frac{\partial}{\partial x}\left(\mu_{\text {eff }} \frac{\partial u}{\partial x}\right)+\frac{\partial}{\partial y}\left(\mu_{\text {eff }} \frac{\partial u}{\partial y}\right)
$$

Y-direction momentum equation:

$$
\frac{\partial}{\partial x}(\rho u v)+\frac{\partial}{\partial y}(\rho v v)=\frac{\partial p}{\partial y}+\frac{\partial}{\partial x}\left(\mu_{\text {eff }} \frac{\partial v}{\partial x}\right)+\frac{\partial}{\partial y}\left(\mu_{\text {eff }} \frac{\partial v}{\partial y}\right)
$$

Where: $\mu_{\text {eff }}$ is the total effective viscosity of the flow, $u, v$, $\mathrm{T}, \mathrm{P}$ are velocity in $\mathrm{x}$ direction, velocity in $\mathrm{y}$ direction and the temperature and the pressure inside the duct, respectively.

Energy equation:

$$
\frac{\partial}{\partial x}\left(\rho C_{p} u T\right)+\frac{\partial}{\partial y}\left(\rho C_{p} v T\right)=\frac{\partial}{\partial x}\left(k \frac{\partial T}{\partial x}\right)+\frac{\partial}{\partial y}\left(k \frac{\partial T}{\partial y}\right)
$$

The above equations are solved with the following boundary conditions in laminar flow as,

The inlet boundary conditions can be written as:

$$
\mathrm{u}=\mathrm{u}_{\mathrm{in}}, \quad \mathrm{T}_{\mathrm{c}, \mathrm{in}}=\mathrm{T}_{\mathrm{h}, \mathrm{in}}=300 \mathrm{~K}
$$

The outlet boundary conditions can be written as:

$$
\frac{\partial \mathrm{u}}{\partial \mathrm{x}}=0, \quad \mathrm{P}=\mathrm{P}_{\mathrm{a}}, \quad \frac{\partial \mathrm{T}}{\partial \mathrm{y}}=0
$$

The maximum error values are $10^{-4}$ for (continuity and momentum) and $10^{-6}$ for energy. Numerical solution of the governing equations is carried using the CFD software package developed by ANSYS-Fluent. First, the geometry is created with ANSYS multi-physics software as a twodimensional base case. Second, mesh is created by discretizing the computational domain into different mesh elements shapes and sizes to maintain minimum skewness and materials were the first fluent input parameters for CFD model base case, then boundary conditions which consist of many parameters such as material name, thermal and type. Third, ANSYS-Fluent is set up parameters for a 3-D flow solution.

1. The ANSYS-Fluent read the case from mesh part, then models-solver, models-energy, models-viscous.

2. Set up of controls-solution for equations, pressurevelocity-energy, under relaxation factors and discretization is done.

3. The system is initialized to start solving.

\section{Results and discussions}

In order to optimize the rate of heat transfer and the COP of the thermoelectric cooling system, various cases are applied, to study the effect of different parameters including supplied power to the TECs modules, inlet water velocity, fluid type with different concentrations of nanoparticles in addition to the number and arrangement of TECs in use. Fig. 5 shows a 3-D model of thermoelectric cooling system from ANSYS-Fluent 18.

\subsection{Mesh independency test}

Reliable numerical solutions are obtained by performing a mesh convergence study using the ANSYS-FLUENT software in order to ensure the grid-independence solutions. This is done by changing the size of elements used (mesh refinement) and running the simulation again until the numerical results converge to a stable value which is mesh independent.

Fig.6 shows the variation of $\mathrm{T}_{\mathrm{c}, \text { out }}$ versus element mesh size for three working TECs with $48 \mathrm{~W}$ power and 0.001 $\mathrm{m} / \mathrm{s}$ inlet velocity. The numerical simulations are performed for seven different element sizes of $0.007 \mathrm{~m}, 0.006 \mathrm{~m}$, $0.005 \mathrm{~m}, 0.004 \mathrm{~m}, 0.003 \mathrm{~m}, 0.002 \mathrm{~m}$ and $0.001 \mathrm{~m}$. Finally, the out cold temperature is mesh dependent for element sizes of $0.004 \mathrm{~m}$, becomes mesh independent for element sizes of $0.003 \mathrm{~m}$. Further reduction of the element size below $0.003 \mathrm{~m}$ does not change the numerical results due to error accumulation in the results. 


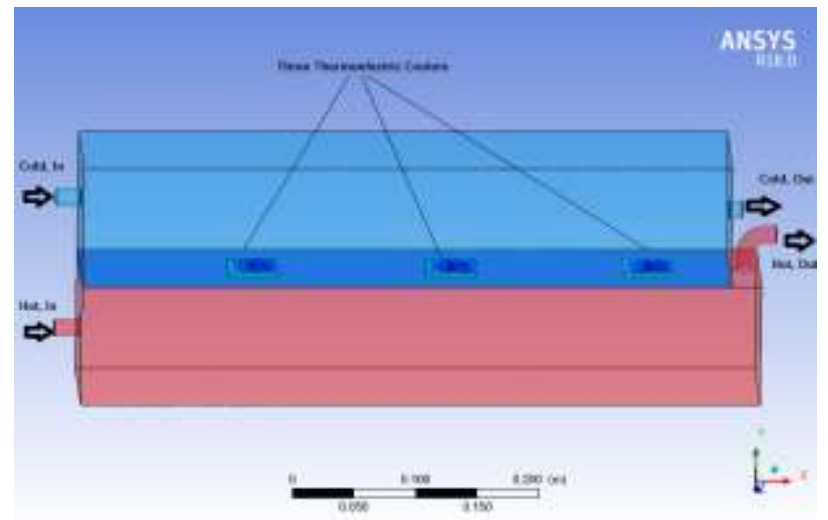

Fig. 5. 3-D model for the thermoelectric cooling system.

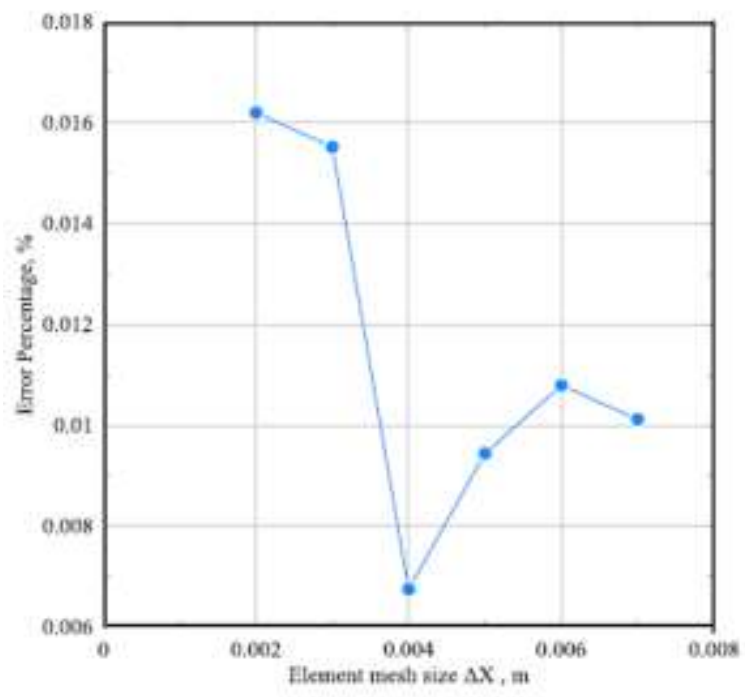

Fig. 6. Variation of the error percentage in $T_{c, \text { out }}$ versus element mesh size for three working TECs with $48 \mathrm{~W}$ power and $0.001 \mathrm{~m} / \mathrm{s}$ inlet velocity.

\subsection{Validation of the present model}

The accuracy of numerical model is verified by comparing the results from present work with the corresponding results reported by Alkaby [17]. In Fig. 7 the coefficient of performance takes a value at small power and is decreased with increasing input power near to $8.0 \mathrm{~W}$, then the COP is increased sharply with input power near to $10 \mathrm{~W}$ and then the value of COP is decreased slightly and takes an asymptotic value with increasing the input power. The cause of decreasing and increasing the COP with input power is due to the migration of electron in the TEC by the input power. The present model shows fairly agreement with the previous model of Alkaby [17], consequently the results of the present model are nearly true.

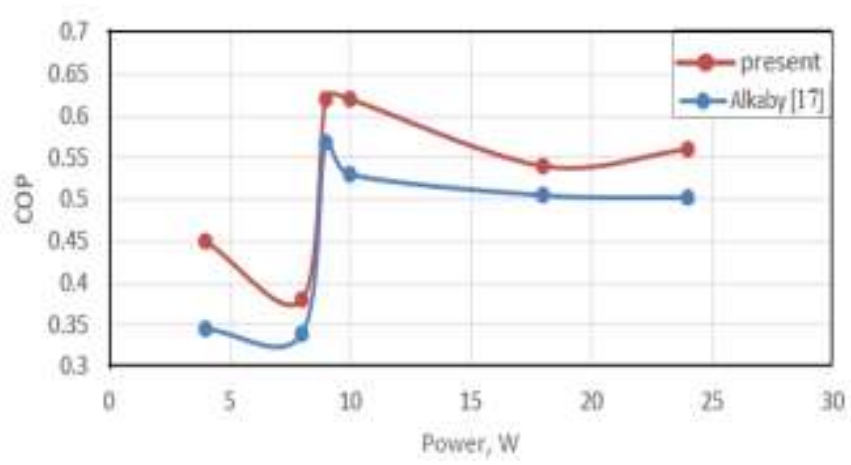

Fig. 7. Comparison between present and previous work.

\subsection{Effect of input power on TEC performance}

To investigate the effect of input power on heat transfer performance and COP of the cooling system, four models are analyzed. The cases with properties are presented in Table 1.

Fig. 8 shows the outlet hot and cold temperatures from the duct for each case in this study. In this figure the outlet hot temperature in the hot fluid side is increased as the power input to TEC increased. While the outlet cold temperature in the cold fluid side is decreased as the input power to TEC increased.

Table 1

Details of case studies performed to investigate the effect of input power.

\begin{tabular}{|c|c|c|c|}
\hline $\begin{array}{c}\text { Case } \\
\text { number }\end{array}$ & $\begin{array}{c}\text { Number } \\
\text { of TECs }\end{array}$ & $\begin{array}{c}\text { Power } \\
\text { (W) }\end{array}$ & $\begin{array}{c}\text { Cold and Hot } \\
\text { side inlet } \\
\text { velocity } \\
(\mathbf{m} / \mathbf{s})\end{array}$ \\
\hline 1 & 3 & 48 & 0.001 \\
\hline 2 & 3 & 40 & 0.001 \\
\hline 3 & 3 & 32 & 0.001 \\
\hline 4 & 3 & 24 & 0.001 \\
\hline
\end{tabular}

Fig. 9 shows that the heat absorbed and the heat rejected for both sides of TEC is increased with input power. Fig. 10 illustrates the coefficient of performance of TEC. Effect of inlet power to TEC make the COP is increased with input power in cold and hot sides. 


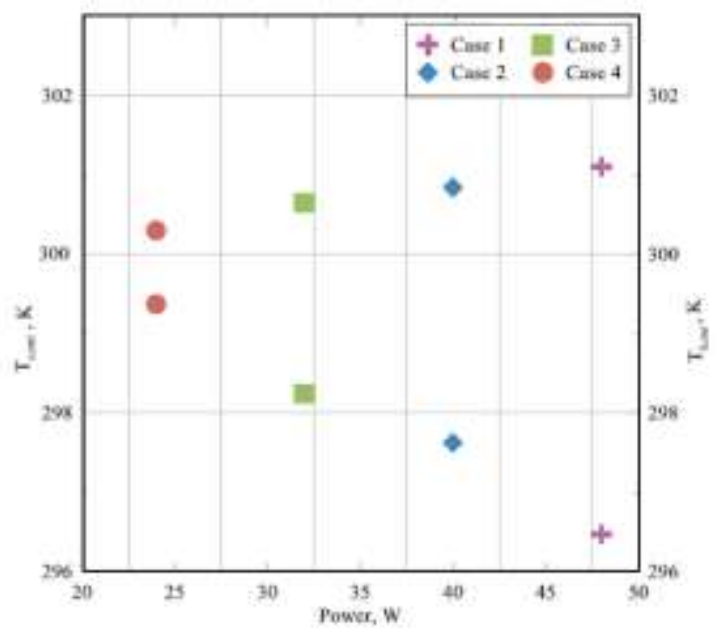

Fig. 8. Relation between outlet hot and cold temperatures with input power for case 1 to case 4.

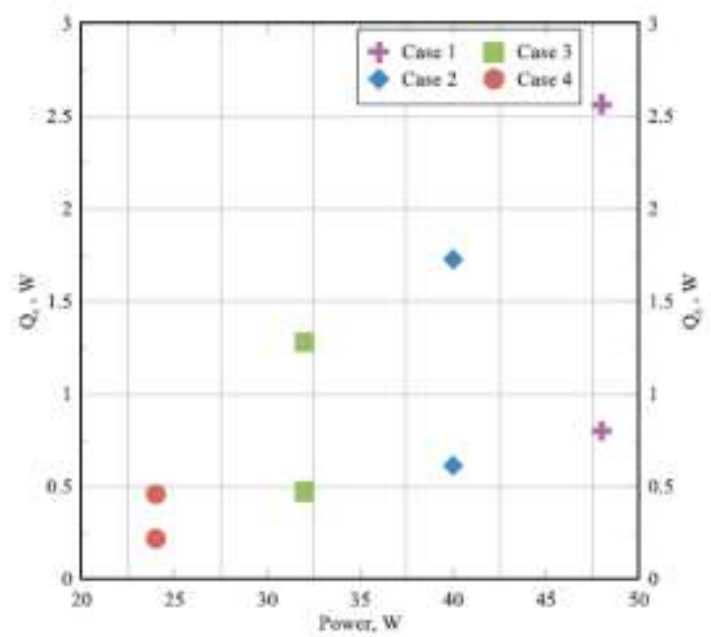

Fig. 9. The variation of $Q_{c}$ and $Q_{h}$ against input power.

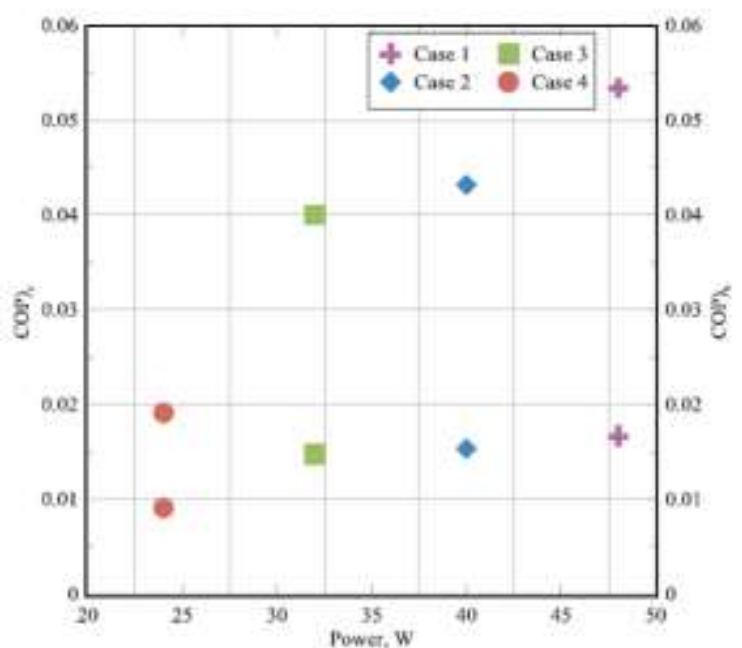

Fig. 10. The variation of COP against input power.

\subsection{Effect of flow inlet velocity on TEC performance}

In order to study the influence of water flow rate on the heat transfer performance and COP of the cooling system. Four cases are performed, where the cases details are presented in Table 2.

Fig. 11 shows the outlet hot and cold temperatures from the duct for each case in this study. In this figure the outlet hot temperature in the hot fluid side is decreased with increasing inlet velocity. While the outlet cold temperature in the cold fluid side is increased with inlet velocity due to the quantity of fluid flow over the TEC that is increased by increasing inlet velocity. Fig. 12 illustrates coefficient of performance of TEC. Effect of flow inlet velocity makes an increase in the COP with inlet velocity increase.

Table 2

Details of the case studies performed to investigate the effect of inlet velocity for $48 \mathrm{~W}$ input power.

\begin{tabular}{|c|c|c|}
\hline $\begin{array}{c}\text { Case } \\
\text { number }\end{array}$ & $\begin{array}{c}\text { Number } \\
\text { of TECs }\end{array}$ & $\begin{array}{c}\text { Cold and Hot side } \\
\text { inlet velocity } \\
(\mathbf{m} / \mathbf{s})\end{array}$ \\
\hline 5 & 3 & 0.002 \\
\hline 6 & 3 & 0.004 \\
\hline 7 & 3 & 0.006 \\
\hline 8 & 3 & 0.008 \\
\hline 9 & 3 & 0.01 \\
\hline
\end{tabular}

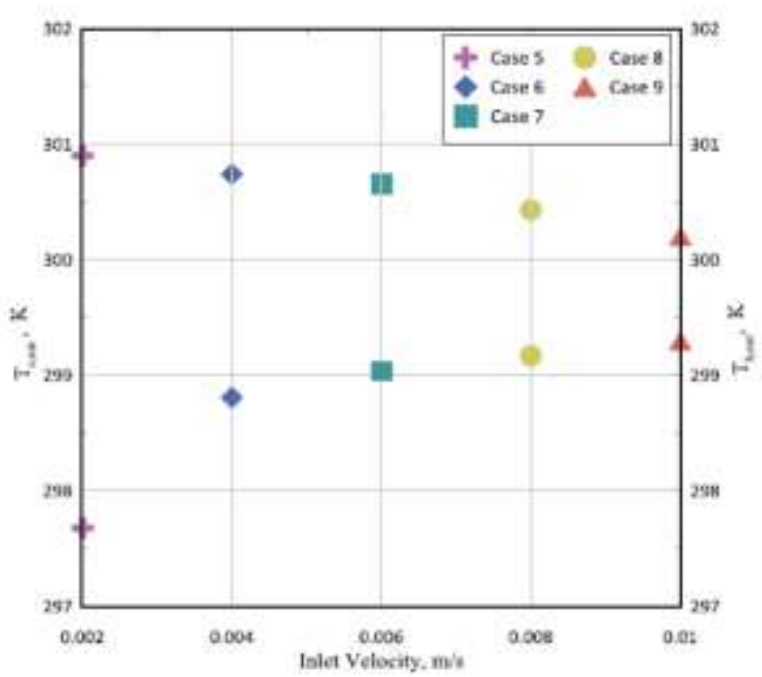

Fig. 11. Relation between outlet hot and cold temperatures with equal hot and cold inlet velocities for case 5 to case 9. 


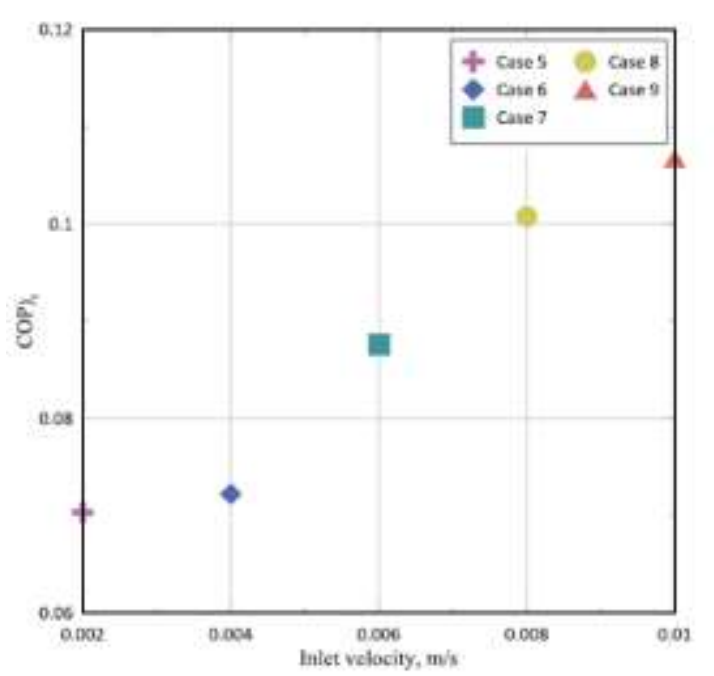

Fig. 12. The variation of COP against inlet velocity.

\subsection{Effect of number of TECs in use on TEC performance}

In order to study the number and arrangement of TEC modules in use on the heat transfer performance and COP of the cooling system, seven case studies are analyzed. The cases details are presented in Table 3 . Table 4 illustrates a comparison between the different arrangement of TEC modules on heat transfer and COP.

\section{Table 3}

Details of the case studies performed to investigate the influence of number and arrangement of TEC modules for $48 \mathrm{~W}$ input power.

\begin{tabular}{|c|c|c|}
\hline $\begin{array}{c}\text { Case } \\
\text { number }\end{array}$ & Number of TECs & $\begin{array}{c}\text { Cold and hot side } \\
\text { inlet velocity } \\
(\mathbf{m} / \mathbf{s})\end{array}$ \\
\hline 10 & Three $(1,2,3)$ & 0.001 \\
\hline 11 & Two $(1,2)$ & 0.001 \\
\hline 12 & Two $(1,3)$ & 0.001 \\
\hline 13 & Two (2,3) & 0.001 \\
\hline 14 & One (1) & 0.001 \\
\hline 15 & One (2) & 0.001 \\
\hline 16 & One (3) & 0.001 \\
\hline
\end{tabular}

\section{Table 4}

Effect of TEC arrangement in work on COP.

\begin{tabular}{|c|c|c|c|c|c|}
\hline $\begin{array}{c}\text { Case } \\
\text { number }\end{array}$ & \multicolumn{3}{|c|}{ Graph } & $\begin{array}{c}T_{c, \text { out }} \\
(\boldsymbol{K}) \\
\end{array}$ & COP \\
\hline 10 & $1=$ & 2 & 4 & 297.6 & 0.011 \\
\hline 11 & 4 & 2 & & 297.4 & 0.019 \\
\hline 12 & 1 & & $\Delta$ & 297.5 & 0.018 \\
\hline 13 & & 2 & 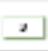 & 297.2 & 0.020 \\
\hline 14 & 1 & & & 299.2 & 0.012 \\
\hline 15 & & $\Rightarrow$ & & 298.9 & 0.015 \\
\hline 16 & & & , & 298.3 & 0.025 \\
\hline
\end{tabular}

Fig. 13 shows that the temperature of hot and cold side is dependent on the inlet power and TEC arrangement. The best point of operation is all of TEC are in work. Also the temperature difference of hot and cold is maximum in this operation but in the arrangement of TEC2 and TEC3 is nearly the optimum operation.

Fig. 14 shows that COP of TEC is dependent on the TEC arrangement of operation. The best arrangement of operation for maximum COP is case 10 where the three TECs are in work.

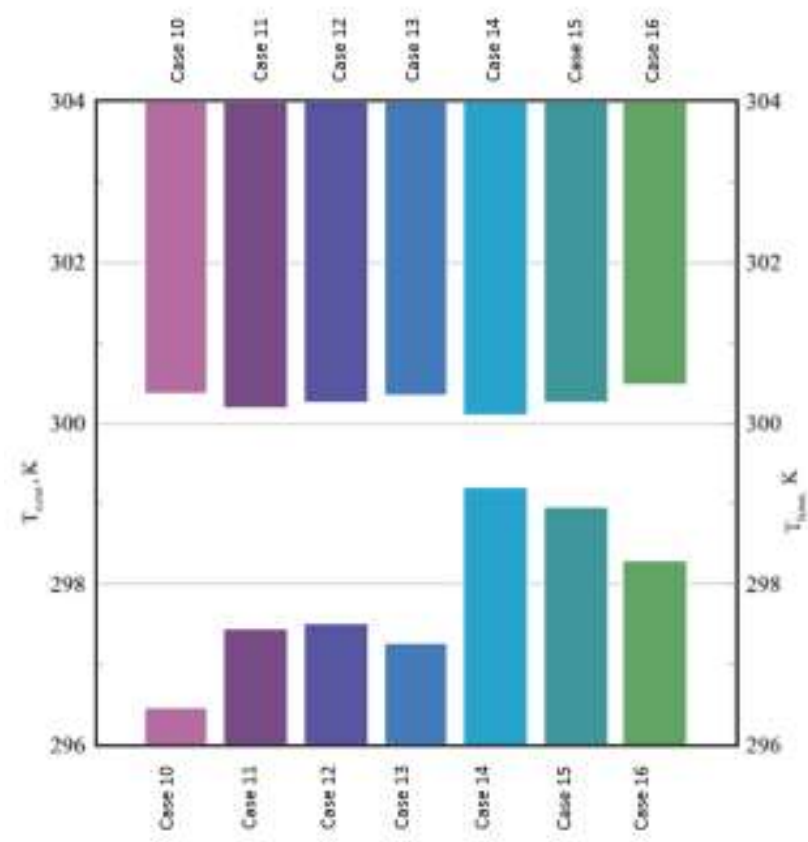

Fig. 13. Relation between outlet hot and cold temperatures with TEC arrangement for case 10,11, 12, 13, 14, 15 and 16. 


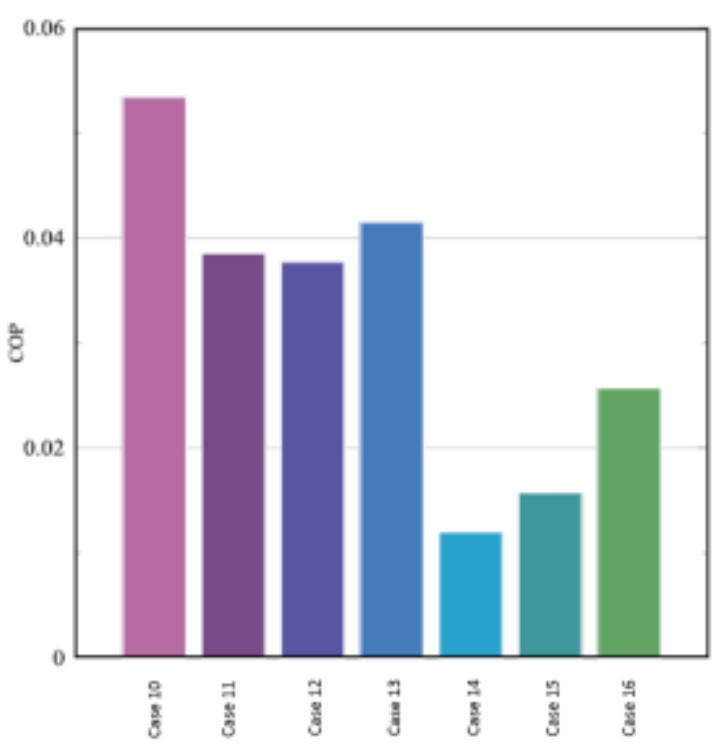

Fig. 14. Relation between COP with TEC arrangement for case $10,11,12,13,14,15$ and 16.

\subsection{Effect of fluid type on TEC performance}

Table 5 shows the details of fluid types that are used as a working fluid. Fig. 15 illustrates temperature in the interface surface for each case with changing the working fluid. The pure water is the best operation of the temperature difference between hot and cold side. The pure water is good coolant in both sides of TEC. Fig. 16 illustrates the effect by fluid type on the COP. The COP of pure water and nanofluid with $0.05 \%$ of nanoparticles takes the maximum value. The use of nanofluid as a coolant fluid on TEC takes the maximum operation of TEC element because it takes the liberated heat on TEC fast as possible. The nano particles are added to pure fluid, it takes the thermal properties is increased as particles lied between fluid particles. The nanofluid has higher thermal properties than the pure fluid.

\section{Table 5}

Details of the case studies performed to investigate the influence of fluid type of TEC system for $48 \mathrm{~W}$ input power.

\begin{tabular}{|c|c|c|}
\hline $\begin{array}{c}\text { Case } \\
\text { number }\end{array}$ & Fluid type & $\begin{array}{c}\text { Cold and hot side } \\
\text { inlet velocity } \\
(\mathbf{m} / \mathbf{s})\end{array}$ \\
\hline 17 & Water & 0.001 \\
\hline 18 & Air & 0.001 \\
\hline 19 & Ethylene-glycol & 0.001 \\
\hline 20 & $\begin{array}{c}\text { Nanofluid }\left(\mathrm{Al}_{2} \mathrm{O}_{3} \text {-Water }\right) \\
\Phi=0.05\end{array}$ & 0.001 \\
\hline$r_{1}$ & $\begin{array}{c}\text { Nanofluid }\left(\mathrm{Al}_{2} \mathrm{O}_{3} \text {-Water }\right) \\
\Phi=0.10\end{array}$ & 0.001 \\
\hline
\end{tabular}

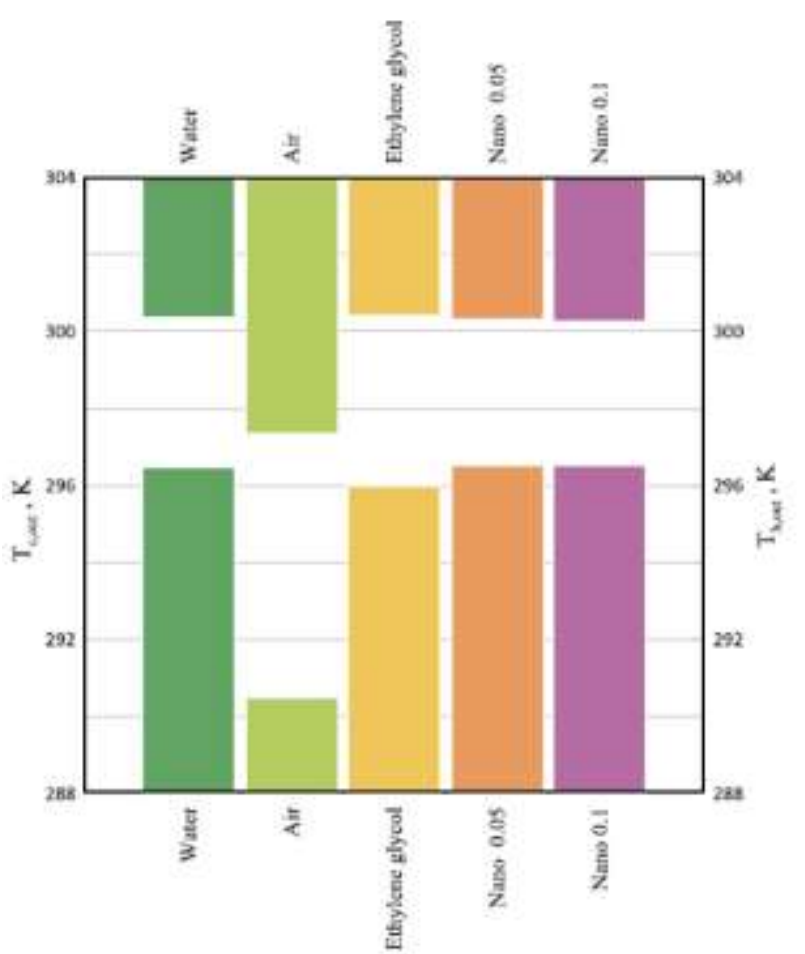

Fig. 15. Relation between outlet hot and cold temperatures with fluid type.

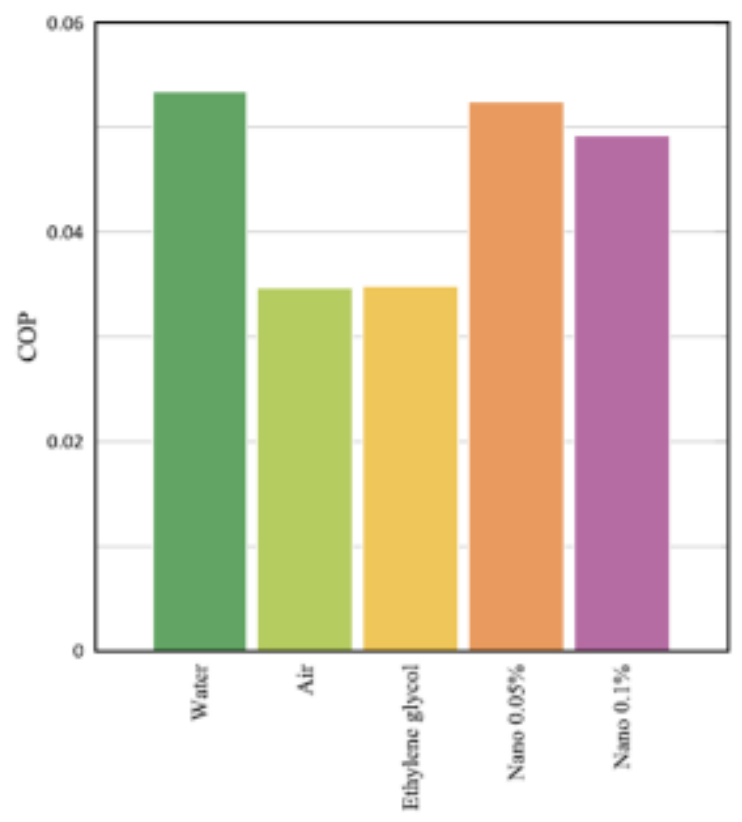

Fig. 16. Relation between COP and fluid type.

\section{Conclusions}

The following conclusions can be drawn:

1. The overall COP of TE cooling system is increased with the applied input power up to $8.0 \mathrm{~W}$ then it 
decreases with input power up to $18 \mathrm{~W}$ after that it takes nearly a constant value.

2. The agreement between this theoretical study and a previous study is found to be fairly agreement.

3. The COP of TE cooling system is increased with flow inlet velocity.

4. The best arrangement of TEC for getting maximum COP is case 10 where there are three TEC in use.

5. The COP of TE cooling system using pure water and nanofluid with $0.05 \%$ of nanoparticles as coolants takes the maximum value.

\section{References}

[1] J.C. Peltier, Ann. Chem. LVI, 1834, 371-387.

[2] W. E. Clifton, Thermoelectric cooling design, Naval Postgraduate School Monterey, California, 1992, 79.

[3] P. Wang, A. Bar-Cohen, B. Yang, L. Solbrekken Gary and A. Shakouri, Analytical modeling of silicon thermoelectric microcooler, Journal of Applied Physics, 2006, 13.

[4] P.k.S.Nain, S. Sharmaand J.M. Giri, Non-dimensional multi-objective performance optimization of single stage thermoelectric cooler, 2010, 10.

[5] E. O. Virjoghe, D. Enescu, M. Ionel and M. Florin Stan, Numerical simulation of thermoelectric system, latest trends on systems, 2010, 6 .

[6] I. Lashkevych and G. Yury Gurevich, boundary conditions for thermoelectric cooling in $\mathrm{p}-\mathrm{n}$ junction, 2011, 12.

[7] M. Redmond, Thermal Management of 3-D stacked chips using thermoelectric and microfluidic devices, Georgia Institute of Technology, 2013, 176

[8] T. Lam, Sidney W.K. Yuan, E. Fong and W. D. Fischer, Analytical study of transient performance of thermoelectric coolers considering the Thomson effect, International Journal of Thermal Sciences, 2018, 435-448.

[9] R. Lamba, S.C. Kaushik, S.K. Tyagi and S. Manikandan, Thermodynamic modelling andperformance optimization of trapezoidal thermoelectric cooler using genetic algorithm, Thermal Science andEngineering Progress, 2018, 43.

[10] D. Richard Harvey, Distributed control to improve performance of thermoelectric coolers, Graduate School of Vanderbilt University, 2005, 69.

[11] Yu. I. Ravich and A. N. Gordienko, A method for calculating the transient time of a multi-stage thermoelectric cooler, Semiconductors, Vol. 41, No. 1, 2007, 5.

[12] E. Elena Antonova and D. C.Looman, Finite elements for thermoelectric device analysis in ANSYS, Southpointe Technology Drive, Canonsburg, PA 15317, USA, 2008, 4.

[13] M. Angel Olivares-Robles, F. Vazquez and C. Ramirez-Lopez, Optimization of two-stage peltier modules: Structure and exergetic efficiency, Entropy, 2012, 14.

[14] Sh. Lin and J. Yu, Optimization of a trapezoid-type two stage Peltier couples for thermoelectric cooling applications, International Journal of Refrigeration, 2015, 24.

[15] T.-Hu Wang , Q.-Hong Wang, Ch. Leng and X.-Dong Wang, Parameter analysis and optimal design for two-stage thermoelectriccooler, Applied Energy, 2015, 1-12.

[16] A. Nemati, H. Nami, M. Yari and F. Ranjbar, Effect of geometry and applied currents on the exergy and exergoeconomic performance of a two-stage cascaded thermoelectric cooler, International Journal of Refrigeration, 2017, 46.

[17] R. N. M. Al-Kaby, Study of thermal performance of thermoelectric cooling system, Babylon University/College of Engineering, 2007, 17.
[18] J. Terry Hendricks and K. Karri Naveen, Micro- and NanoTechnology: A critical design key in advanced thermoelectric cooling systems, Journal of Electronic Materials, Vol. 38, No. 7, 2009, 11.

[19] J. Long and S. Ogrenci Memik, A framework for optimizing thermoelectric active cooling systems, 2010, 6 .

[20] A. Gallo, A. Arana, A. Oyanguren, G. Garcia, A. Barbero, J. Larranaga and I. Ulacia, Numerical modeling and design of thermoelectric cooling systems and its application to manufacturing machines, Journal of Electronic Materials, Vol. 42, No. 7, 2013, 5.

[21] O. Francis, Ch. Jeremiah Lekwuwa and I. Harrison John, Performance evaluation of a thermoelectric refrigerator, International Journal of Engineering and Innovative Technology (IJEIT) Vol. 2, Issue 7, 2013, 7.

[22] M. Azimi, S. Sajad Mirjavadi and M. Sedighi, A Novel cooling system design for water block in liquid cooling garment, Journal of Science and Engineering, Vol. 07 (01), 2016, 11.

[23] S. Manikandan, S.C. Kaushik and R. Yang, Modified pulse operation of thermoelectric coolers for building coolingapplications, Energy Conversion and Management, 2017, 145-156.

[24] X. Sun, L. Ling, Sh. Liao, Youhong Chu, S. Fan and Y. Mo, A thermoelectric cooler coupled with a gravity-assisted heat pipe: Ananalysis from heat pipe perspective, 2018, 230-242.

[25] Y. Cai, Sh. Mei, Di Liu, Fu-Yun Zhao and Han-Qing Wang, Thermoelectric heat recovery units applied in the energy harvest builtventilation: Parametric investigation and performance optimization, Energy Conversion and Management, 2018, 1163-1176.

[26] R. Boukhanouf and A. Supasuteekul,Theoretical analysis of an integratedthermoelectric-absorption cooling system, International Journal of Low Carbon Technologies, 2018, 13. 